\title{
Cross-Sectional Study Design and Data Analysis of the Effect of Chitin Nanofibrils- Lignin Micro/Nano Particles on Malaysia's Subjects with Skin Disorders
}

\author{
Yeo Yip Jui ${ }^{1}$, Tan Lee Chin $^{1}$, Tan Siok Ing $^{1}$, Cardillo $\mathrm{M}^{2}$, Gagliardini A ${ }^{3}$, and P Morganti ${ }^{4 *}$ \\ ${ }^{1}$ Imprees Esteem Academy, Melaka, Malaysia \\ ${ }^{2}$ Dermatologist ISCD Nanoscience Center R\&D, Rome, Italy \\ ${ }^{3}$ R\&D Atertek, Pescara, Italy \\ ${ }^{4}$ Dermatol Unit, Campania University, Naples, Italy
}

*Corresponding author: P Morganti, Dermatol Unit, Campania University, Naples, Italy, Tel: 390815666833; E-mail: pierfrancesco.morganti@iscd.it

Received: 19 Jan, 2019 | Accepted: 07 Mar, 2019 | Published: 13 Mar, 2019

Citation: Jui YY, Chin TL, Ing TS, Cardillo M, Gagliardini A, et al. (2019) Cross-Sectional Study Design and Data Analysis of the Effect of Chitin Nanofibrils-Lignin Micro/Nano Particles on Malaysia's Subjects with Skin Disorders. J Clin Cosmet Dermatol 3(2): dx.doi.org/10.16966/25762826.139

Copyright: (C) 2019 Jui YY, et al. This is an open-access article distributed under the terms of the Creative Commons Attribution License, which permits unrestricted use, distribution, and reproduction in any medium, provided the original author and source are credited.

\begin{abstract}
Objective: The Objective of the paper is to control the activity of innovative Cosmetic products, classified as Cosmeceuticals because of their particular effectiveness and used alone without consume of drugs, to verify their efficacy on subjects affected by acne, contact dermatitis, and photoaging. After an introduction reporting some data on the cosmetic market in Malaysia and their habit of mind to attend the Beauty Centers before going to dermatologist, we report the method of treatment by cosmetic products organized by 90 voluntary subjects, divided in three groups of 30 subjects, affected by photo-aging, acne and contact dermatitis respectively. They were treated for 90 days and two times a week into a Malaysian Beauty center by different Cosmetic emulsions based on the use of chitin nanofibrils-lignin micro/nanoparticles bound to different selected active ingredients, such as nicotinamide, antioxidants and glycolic acid. The same products were used at home in the morning and evening for all the in study period. Treatments into the Beauty Center and at home were under the control of a Dermatologist and expert beauticians for all the period of experimentation and the control was verified by the score method and photosat the starting day and after 30,60, 90 days of treatment and 120 days (follow up visit). The obtained results, controlled by a dermatologist by score methods and photos, have shown the possibility to use well formulated cosmetics to try to ameliorate the reported diseases, without the use of topical and/or systemic drugs. In conclusion, these innovative cosmeceutical, used by the help of expert beauticians, may be of great help to Dermatologists and Plastic surgeons to solve some skin problems, avoiding the use of drugs, or limiting their doses to lessen the risk of harmful side effects.
\end{abstract}

Keywords: Acne; Aging; Photoaging; Contact dermatitis; Chitin nanofibrils; Nanolignin; Cosmeceuticals

\section{Introduction}

\section{Market}

Malaysia's total trade volume for personal care and Cosmetic products was about US\$2.24 billion in 2015 [1]. In this sectors the make-up and skin-care products categories exhibit the greatest demand, of which over $50 \%$ is represented by imported products (Tables 1,2) [2,3].

As of 2016 Malaysia's population size is 31.3 million, about $70 \%$ of which are urban dwellers who are also the majority of consumers. They are in the range age of 12-25 years, prevalently female, with a high school or higher education level and a pro capita income of 9.76 US\$ [1-3].

Due to the more affordable price, the younger generation of females purchase Korean branded products, while 25-54 age group is more open to US, EU, Australian and Japanese cosmetics. The number of skin-care products used for this age group is around 4 to 8 including cleanser, toner, moisturizers, sunscreen, and acne treatment with the mayor selling for sunscreen / whitening / anti-aging / brightening of blemish and acne scars.
On the other hand, the consumer-male is more inclined towards basic grooming, and hair styling products, while a big proportion of this group can be classified in the metrosexual category. It is also to remember that the products formulated for the Malaysia's market and its consumers have not to leave a tacky after feel and must withstand heavy humidity and hot air for all the year long.

\section{Products requested and used in the beauty centers}

It is interesting to underline that the female to male consumer ratio for facial / spa treatment is around 3:1, and female are more discerning and trend towards natural cosmeceuticals and the environmental protection. Among the products, the noninvasive anti-aging cosmetics and anti-inflammatory and acne therapies are the more used and preferred to the use of drugs.

Thus, the majority of treatments in the beauty centers are generally based on the use of cosmeceuticals based on natural ingredients, presented in the form of ampules, serums and emulsions utilized by massage and the frequent use of LED, mesotherapy, laser therapy, and ultrasounds. 
Table 1: 2013 Cosmetic total import value in Malaysia.

R013 COSMETIC TOTAL IMPORT VALUE IN MALAYSIA

USS million

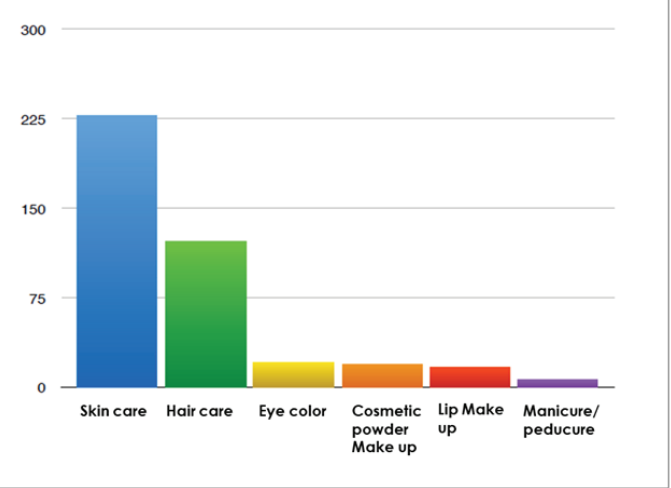

Table 2: Import value of Cosmetic Market Imported in Malaysia.

IMPORT VALUE OF COSMETIC MARKET IMPORTED IN MALAYSIA

US\$ million

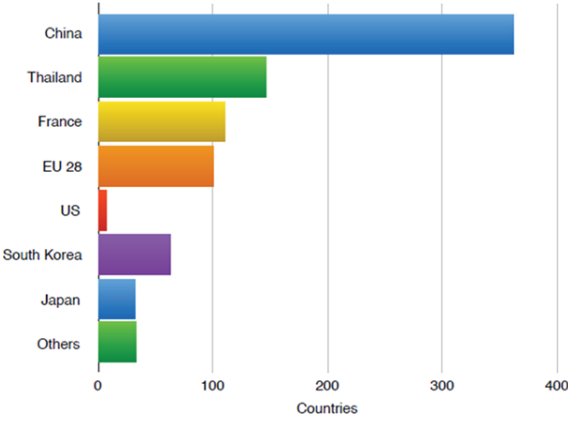

\section{Aims}

The first aim of this study has been to control the safety, tolerability and effectiveness of Italian innovative cosmeceuticals, for treating mild diseases such as acne, contact dermatitis and premature aging by the combined use of different active ingredients bound into or in the surface of Chitin Nanofibril-Hyaluronan and Chitin nanofibrilNanolignin (selected as carriers). The main active agents were Glycolic acid with azelaic acid, nicotinamide and antioxidant compounds, respectively applied by manual massage. Naturally, all the cosmetics utilized were previously controlled by in vitro methods for verifying their safeness and effectiveness. The second aim, in fact, was to select cosmetic products and methodologies necessary and able to support and increase the effectiveness of drug procedure executed into the Dermatologist and Plastic surgeon offices.

\section{Materials and Methods}

\section{Study designs}

One month before and during the period of treatment no drugs nor other cosmetic products were used from the selected subjects, the skin of which was controlled from an expert dermatologist, before starting the study and each every 15 days during all the 90 days period.

A group of 90 healthy voluntary women (18-45 aged) were selected in our beauty center, 30 of which presented acne with and without scars, 30 mild contact dermatitis some time with presence of eczema and, 30 fine lines and wrinkling [4-6], characterizing the aging and photo aging phenomena of this group [7-10]. All the subjects gave their written consent to the experimental protocol and, according to the declaration of Helsinki revised in Seul, were treated by our previous methods [8-11]. They were selected from a dermatologist and an expert beautician with experience of more than 15 years, with control visit and measurements performed at day 1 (D1 study starting), 30, (D30), 60 (D60), 90 (D90) and again at 120 (follow up visit), by visual score methodologies followed by photos of the relative skin areas.

All the subjects, laid-back on a specialized massage table of the Esteem Academy' beauty center and positioned in a location at controlled temperature $\left(\mathrm{t}=22^{\circ} \mathrm{C}\right)$ and humidity $(\mathrm{RH}<=50 \%)$, were treated for about one hour and two times a week, after a previous 20 minutes of rest.

During the treatment period, all the subjects were instructed to apply the products at home twice a day in the morning and just before retiring in the evening, at least $30 \mathrm{~min}$ after cleansing with the specific products supplied. The treatment period lasted 12 weeks during which no other cosmetics or drugs were to be used, and exposure to strong sunlight was avoided.

About the clinical score method, a 0-10 visual analogue scale was used for Photoaging, evaluating the degree of correction of fine lines and wrinkling in the different face areas $(0=$ no correction, $10=$ total correction), according to our previous results [11]; the same 0 - 10 scale was used to evaluate both the acne score, according to the grading erythema and the gravity of lesions [12] and the contact dermatitis [13]. The reported photographic pictures were taken at day $1^{\text {st }}$ and at day $90^{\text {th }}$.

\section{Statistical analysis}

The homogeneity of variance test was used to compare subject's ages, total wrinkles and fine, lines, grade of irritation and acne score before treatment, Student's $t$ test and one-way analysis of variance were used to compare the significance of the mean percentage improvement between the different treatment groups at different times, The chisquared test was used to compare the treatments success rates after the treatments of the different groups. For all comparisons, significant level of $0.05(\mathrm{p}<0.05)$ was used. Results are represented as the mean +/- standard deviation.

\section{Photo-aging and whitening treatment}

Skin physiology, skin aging and photo-aging are very complex processes where environmental factors and the life style result of great importance. Thus, the chronic exposure to nanoparticulate, chemicals and ozone as part of photochemical smog [14,15], aggravate the further cutaneous damage induced by the concomitant UV rays [11], as $t$ results clearly evident in all the Malaysian city-territory. Thus the necessity of preventive measures by the use of cosmeceuticals which, based on natural protective and effective ingredients, may result able to protect the skin from these daily chemical aggressions [16,17], and possibly possessing characterized a whitening activity also [7].

Aged skin was before cleaned by a special emulsion enriched by collagen and hyaluronic acid, soon after treated by a $30 \%$ water solution of glycolic acid [18] for few minutes, and washed by a water/ gel solution witch-hazel-based. On the cleaned skin was applied, by a soft, massage, an emulsion based on hyaluronic acid, collagen, gelatinglycine $[16,19,20]$ and chitin nanofibril-hyaluronan complexes, entrapping nicotinamide, Vitamin $\mathrm{C}$ and $\mathrm{E}$ as active ingredients and enriched by unsaturated fatty acids. 
Treatments were repeated twice a week for 90 days. All the subjects applied on the skin a sunscreen emulsion with a protective activity of 50+ during their stay outside home, for protecting the skin from exposure to environmental elements, in particular the UV radiation. At home, in the morning they used the same emulsion using into the center, i.e. the collagen-gelatin in the morning, while in the evening they applied the Hyaluronan-vitamin ones.

The obtained results are reported on figures 1-4.

\section{AGING SCORE ON PHOTOAGED SKIN}

Score

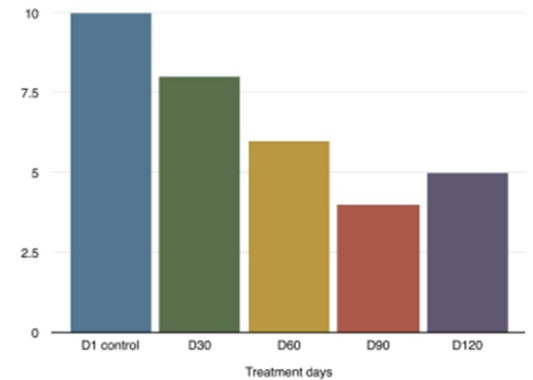

Figure 1: Acne score grading on photoaged skin.

$\mathrm{D} 1$ vs $\mathrm{D} 30=$ significant $(\mathrm{P}<0.05) ; \mathrm{D} 1$ vs $\mathrm{D} 60, \mathrm{D} 90$ and $\mathrm{D} 120=$ highly significant $(P<0.005) ; D 90$ vs D120 $=$ not significant
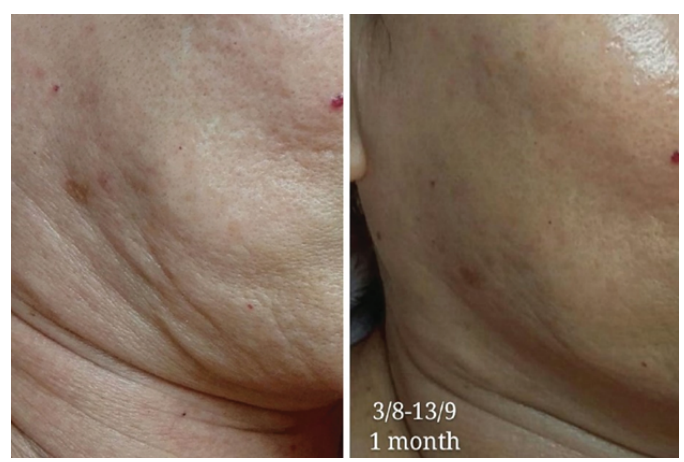

Figure 2: Photoaging lines before treatment (left) and after treatment (right) where the reduction of fine lines is evident.

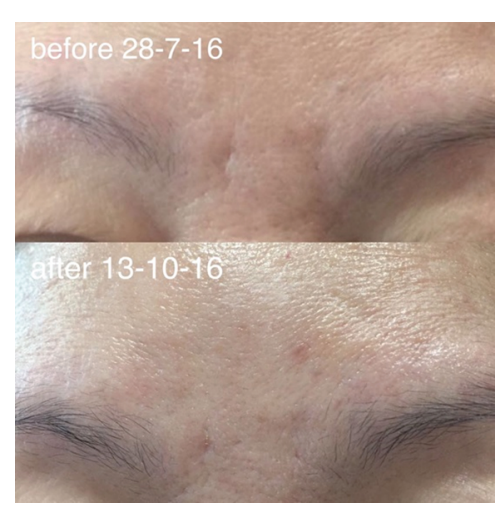

Figure 3: Photoaging (glabellar lines) before treatment (upon) after treatment (below).

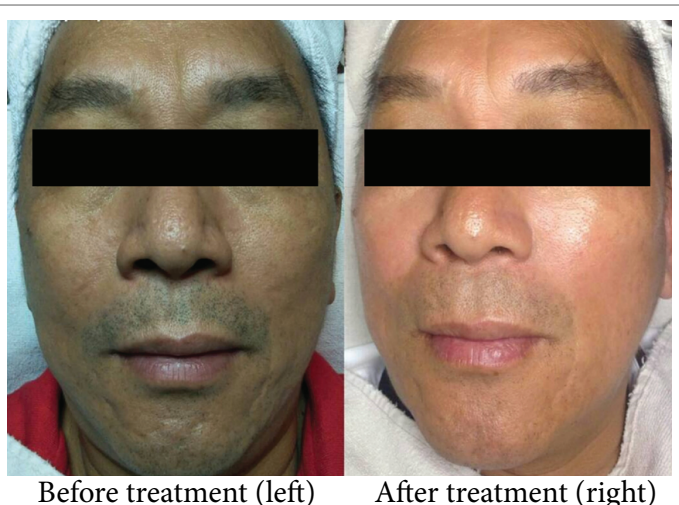

Figure 4: photoaging (hyperpigmentation) on the area of chin and superior lip.

Also, if the photo has been taken with a different light the whitening activity is evident enough.

However, the global antiaging treatment, evidenced first of all by the reduction of fine lines and the hyper pigmented areas, has been confirmed by the score method, especially during the $60^{\text {th }}$ and the $90^{\text {th }}$ day. Moreover during the follow visit, at the day $120^{\text {th }}$ after the treatment intermission, the activity has been maintained at the same level showing the effectiveness of the cosmeceuticals used.

\section{Anti-acne treatment}

Acne is one of the top skin pathology which, affecting in 2015, 633 million people of different age especially in puberty, represents the $8^{\text {th }}$ most common disease worldwide [20,21]. It is characterized from an increased sebum production and keratinization phenomena around the follicular duct, with an increased proliferation of Propionibacterium acne, accompanied by inflammation phenomena with an oily skin and an unusual dry skin sensation, caused by abnormal Trans Epidermal Water Loss (TEWL). Thus the necessity to modulate both the sebum production and the bacteria proliferation by the right cosmetic treatment.

The subjects affected by acne were asked to don't consume during the treatment period certain food such as chili, milk, fried food, wine, or liquor.

Moreover, during the treatment into the beauty center, for trying to control the microbiota population and the free fatty acid in excess, the skin was before cleaned by a water solution with antibacterial activity and an emulsion able to decrease sebum and Free Fatty Acids (FFA) in excess. Soon after, by a soft massage and the use of a light LED device, it has been possible to remove and modulate more easily both FFA and dead cells from clogged pores, increasing also the penetration of the emulsion's active ingredients [22]. An emulsion based on chitin-lignin micro/nanoparticles entrapping niacinamide [23-26], phosphatidylcholine [27,28] and azelaic acid [29], was applied together with a water solution of specific plant's active compounds, such as Chirthmum maritimum and the witch/hazel extracts [30]. The same home treatments and the use of the sunscreen are mandatory for all.

The obtained results are reported by figures 5-10.

In both the figures $7^{\text {th }}$ and $8^{\text {th }}$ the scars appear less evident showing an interesting improvement since the day $60^{\text {th }}$, confirming what has been well evidenced from the score method (Figure 5). Also in these cases the cosmetic treatments effectiveness has continued at the day $120^{\text {th }}$, during the intermission of the care.

In the more difficult treatment of the pustular acne reported on figures $9^{\text {th }}$ and $10^{\text {th }}$ the results shown have to be considered interesting, because obtained by the only cosmetic treatment, without the use of any drug. 


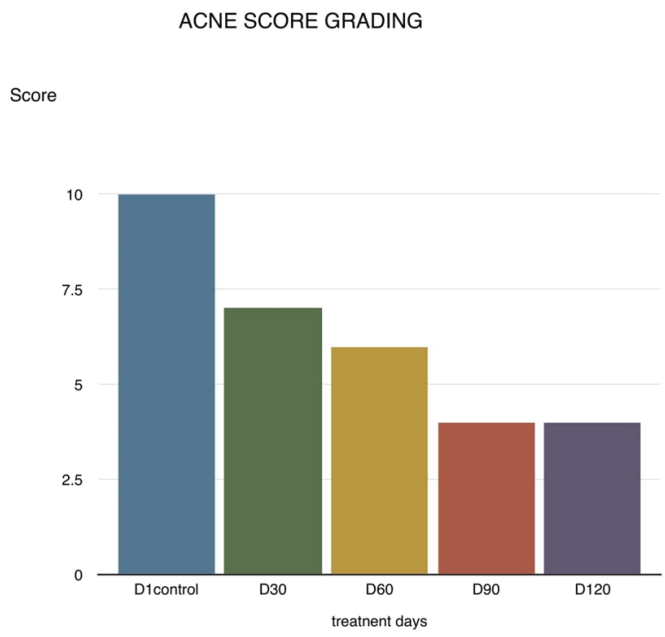

Figure 5: Acne score grading.

$\mathrm{D} 1$ vs D30, D60, D90 and D120=highly significant $(\mathrm{P}<0.005)$; D30 vs D60 not significant; D30 vs D90 and D120=highly significant $(P<0.005)$; D90 vs D120=not significant.
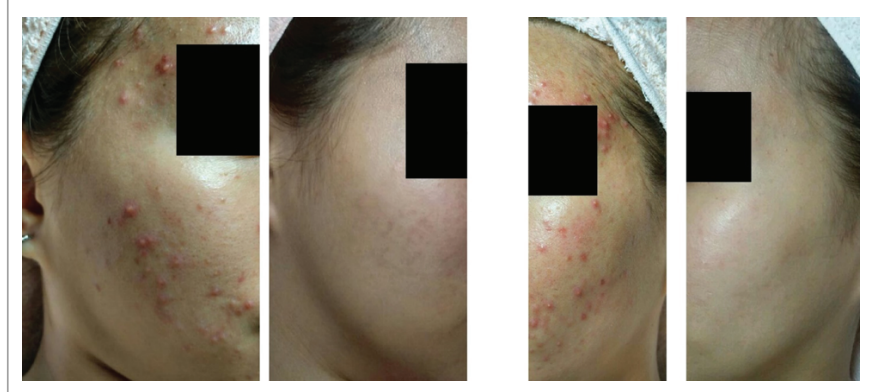

Figure 6: Acne vulgaris where the evident presence of many inflamed pimples located in both the cheek areas, before the treatment (left), is reduced at zero after the treatment at the day 90 (right).

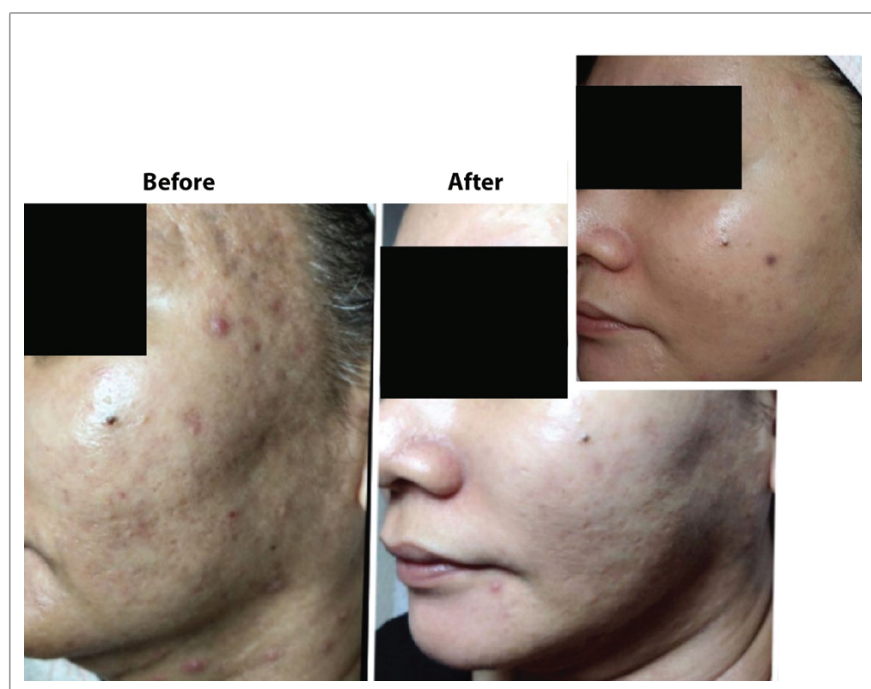

Figure 7: Acne vulgaris with scars. Also in this case pimples and scars (left) are notably improved during the treatment (right).
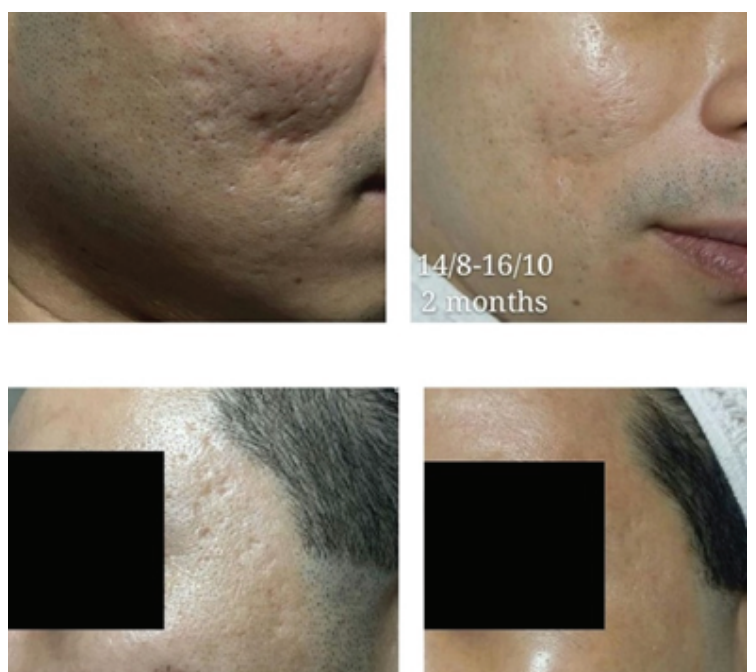

Figure 8: Acne scars before treatment (left) and after treatment (right).

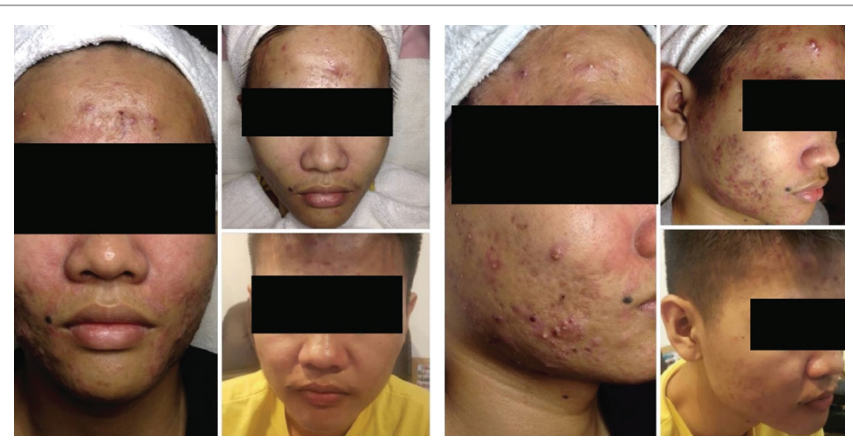

Figure 9: Pustular acne before treatment (left) and after treatment (right).

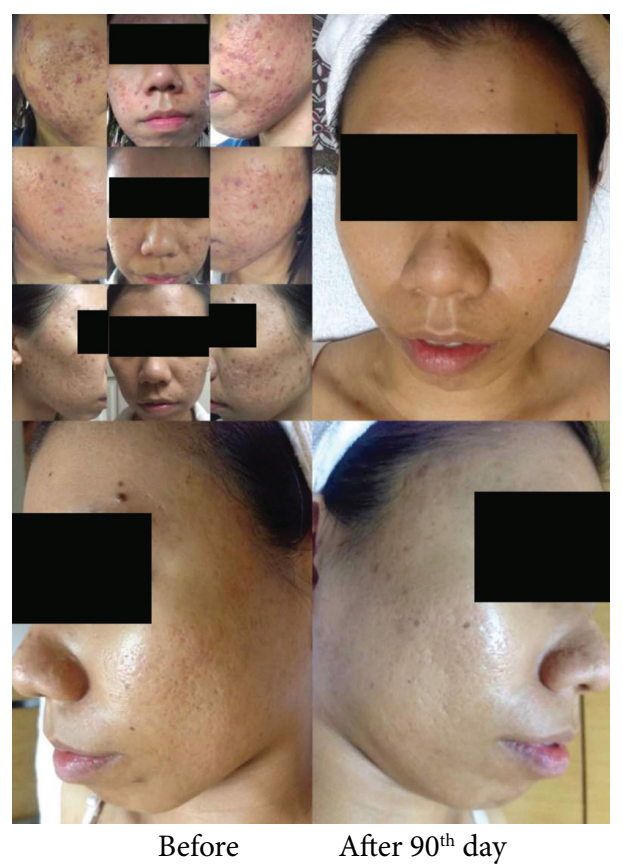

Figure 10: Pustular acne before (upon) and after treatment (below) and on the right. 


\section{Anti-inflammatory treatment}

Contact dermatitis, also known from people as eczema or rash [31], is a group of diseases that results in skin inflammation characterized by itchiness, red appearance, and rush. Normally people go to the dermatologist but in Malaysia, many people go as first option to a beauty center and later to the Dermatologist office. Additionally, the dermatologist prescribes the first drugs and sends the patient to the beauty center for further treatments. Thus, many subjects are coming in our center to treat different inflammatory processes caused by cosmetics or chemicals' contact.

In our beauty center contact dermatitis and other skin inflammation phenomena are treated by a witch hazel gel used as cleaning agent also, necessary to quickly decrease the inflammatory process. This treatment is followed by the use of an emulsion based on zincum oxide and the further use of an emulsion made by chitin nanofibrillignin micro/nanoparticles entrapping anti-inflammatory botanical extracts rich of polyphenol and flavonoid compounds [32]. Both the emulsions are applied by soft massage and the use of LED light therapy to increase the skin penetration of the active ingredients.

At home, the subjects have applied twice a day a sunscreen with an SPF of $50+$ (for going outside only), with the same emulsions used in the Center. The obtained results are reported in the figures 11-13.

As shown from the reported photos in both figures $12^{\text {th }}$ and $13^{\text {th }}$, the skin results normal and the inflammation phenomena have been completely disappeared after 90 days of treatment, confirming what is evident by the score grading reported in figure 11 In the case of topic dermatitis the resolution of the disease has been more difficult and the real results are more evident from the Day $90^{\text {th }}$, however persisting at the day $120^{\text {th }}$, during the intermission of the cosmetic treatment.

\section{Results and Comments}

As previously reported, people are coming at the Institute to solve different skin problems which generally they have from many years. The majority of the treated subjects are living in the cities all year around, under the influence of air pollutants, strong sun and high humidity and they are always looking for quick results, not easy to obtain. Many of them suffer for Acne or Contact Dermatitis, but all are looking to rejuvenate their appearance also.

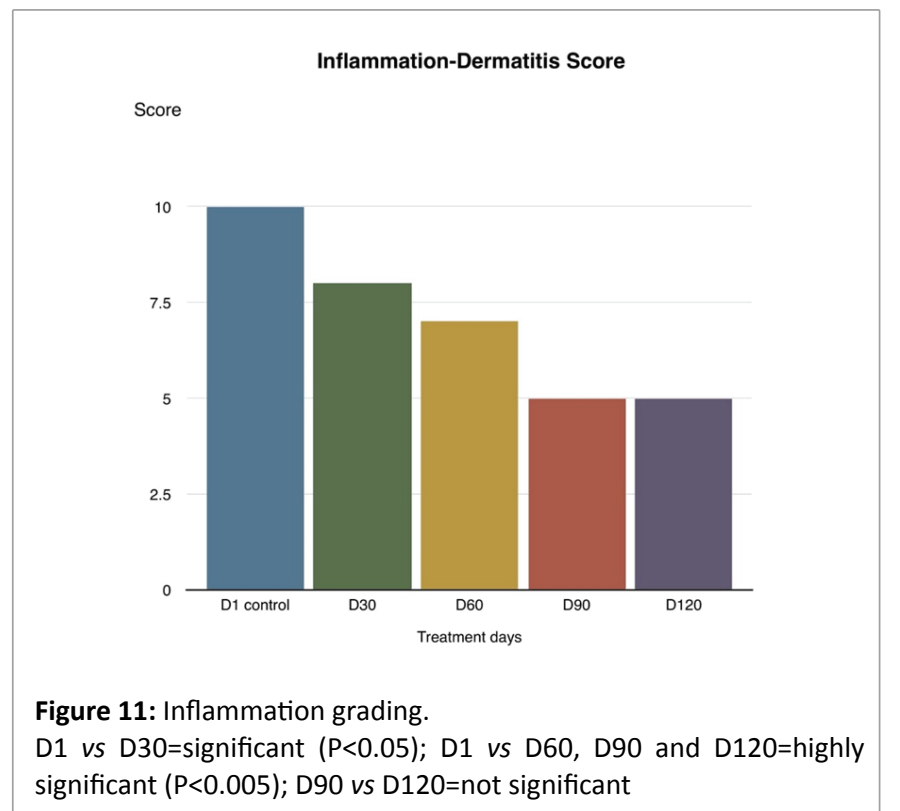

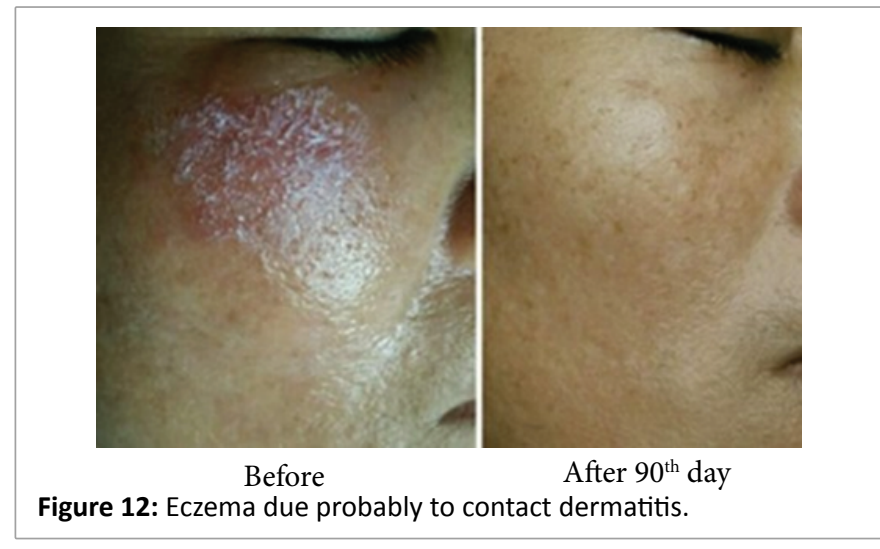

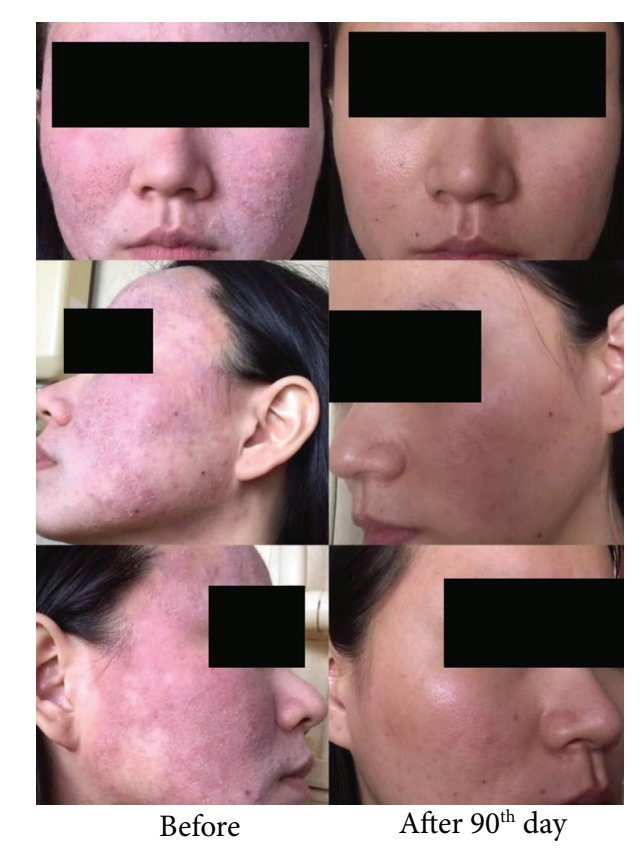

Figure 13: Topic dermatitis before (left) and after treatment (right).

The skin visibility, with its focal point, face and scalp, means that any skin alteration can create psychological rebounds also, not depending to the real seriousness of the pathological lesion and the esthetic damage it could provoke. For a person with skin problems, such as acne or eczema the products able to mask or ameliorate the pathological alterations can strikingly improve appearance and thus benefit the subject psychologically. Thus, it is necessary to offer a relaxant environment, using a range of nature-inspired treatments with the right cosmeceuticals to meet individual needs, according to the actual market requests in our country.

As shown by this study, it has been possible to obtain interesting results treating by the use of the sole specialized cosmeceuticals, not only subjects affected by acne juveniles, but also affected by a more serious disease such as topic dermatitis. Moreover, all the subjects remained satisfied for their more juvenile appearance obtained after the treatments.

The results reported by this study have shown the possibility to treat some mild diseases using only well formulated cosmetics without the need to use drugs or to reduce or alternatively having the possibility to reduce or limit the drug doses necessary for lessening the risk of side effects. 
Thus, according to our way of working and the cosmeceuticals selected, the results on acne, skin aging and eczematous Inflammation reported in figures 1-14 gave us the possibility to collaborate with the offices of dermatologists and plastic surgeons of our country.

Our goal is to ameliorate day by day our methodologies, tools, and cosmetic treatments for trying to solve the many dermatological problems, which come to our attention in strict collaboration with the medical, community.

\section{Acknowledgments}

We have to thank MAVI SudSrl (Aprilia, LT), Italy for the samples given and used for the study and Imprees Esteem Academy, (Melaka, Malaysia), for the organization of this experimental project.

\section{References}

1. Gerstle T (2016) Asia Personal Care \& Cosmetic Market Guide 2016. Report of USA Department of Commerce, Washington DC USA.

2. Hassali MA, Al-Tamimi SK, Dawood OT, Verma AK, Saleem F (2015) Malaysian Cosmetic Market: Current and Future Prospects. Pharmaceut Reg Affairs 4: 155.

3. Statista. Imported value of the personal care and Cosmetic market in Malaysia in 2015 by country. Statista Data, UK.

4. Sarkar R, Arora P, Garg KV (2013) Cosmeceuticals for hyperpigmentation: What is available? J Cutan Aesthet Surg 6: 4-11.

5. Morganti P, Del Ciotto P, Carezzi F, Guarneri F, Yip Jui Yeo (2014) Skin Lightening Efficacy of New Formulations Enhanced by Chitin Nanoparticles Delivery System. Note I, J Appl Cosmetol 32: 57-71.

6. Clark AC, Sivamani PK (2016) Phytochemicals in the Treatment of Hyperpigmentation. J Botanics: Target and Therapy 6: 89-96.

7. Krutmann J, Gilchrest BA (2006) Photoaging of Skin. In: BA Gilchrest, J Krutmann (Eds) Skin Aging. Springer, Germany, 33-43.

8. Morganti P, Palombo P, Palombo M, Fabrizin G, Slovacchia F, et al. (2012) A phosphatidylcholine Hyaluronic acid Chitin-nanofibril complex for a fast skin Remodelling and a Rejuvenating look. Clin Cosmet Investig Dermatol 5: 213-220.

9. Morganti P, Palombo M, Fabrizi G, Guarneri F, Slovacchia F, et al. (2013) New insights on Anti-aging activity of Chitin NanofibrilHyaluronan block co-polymers entrapping active ingredients: in vitro and in vivo study. J Appl Cosmetol 31: 1-29.

10. Morganti P, Palombo M, Tishchenko G, Yudin VE, Guarneri F, et al. (2014) Chitin-Hyaluronan Nanoparticles to deliver Anti-Aging Ingredients through the skin. Cosmetics 1: 149-158.

11. Pietro AD, Fabrizi G, Giaroli U, Tiberi L, Bruno C, et al. (1998) Role of Hyaluronic acid and Vitamin C in Photoaging. J Appl Cosmetol 16: 125-133.

12. Dothan B, Kumari R, Thappa DM (2016) Scoring Systems in Acne Vulgaris. Indian J Dermatol Venereol Leprol 75: 323-326.

13. Farage MA, Maibach HI, Andersen KE, Lachapelle JM, Kern P, et al. (2011) Historical perspective on the use of visual grading scales in evaluating skin irritation and sensitization. Contact Dermatitis 65: 65-75.

14. Schroeder P, Schieke SM, Morita A (2006) Premature Skin Aging by Infrared Radiation, Tobacco Smoke and Ozone. In: BA Gilchrest, J Krutmann (eds) Skin Aging, Springer, Germany: 46-53.
15. Pandel R, Polysak B, Godic A, Dahmane R (2013) Skin photoaging and the role of antioxidants in its Prevention. ISRN Dermatol 2013: 930164.

16. Morganti P (1994) The Protective and Hydrating Capacity of Emollient Agents in the Anti-Aging Treatment of the Skin. J Appl Cosmetol 12: 25-30.

17. Kostyuk V, Potapovich A, Albuhaydar AR, Mayer W, De Luca C, et al. (2018) Natural Substances for Prevention of Skin Photoaging: Screening Systems in the Development of Sunscreen and Rejuvenation Cosmetics. Rejuvenation Res 21: 91-101.

18. Morganti P, Randazzo SD, Palombo P, Bruno C (1994) Topical Gelatine-Glycine and Alpha-Hydroxy Acids for Photoaged skin. J Appl Cosmetol 12: 1-10.

19. Morganti P (1996) Alpha Hydroxy Acids in Cosmetic Dermatology. J Appl Cosmetol 14: 35-41.

20. PR Newswire (2018) Global acne market report for 2026-2026.

21. Tan JK, Bhate K (2015) A global perspective on the epidemiology of acne. Br J Dermatol 172: 3-12.

22. Zaenglein AL, Pathy AL, Schloner BS, Alikhan A, Baldwin HE, et al. (2016) Guidelines of care for the management of acne vulgaris. J Am Acad Dermatol 74: 945-973.

23. Matts PJ, Oblong JE, Bisset DL (2002) A review of the range of effects of niacinamide in human skin. IFSCC Magazine 5: 285-289.

24. Kaymak Y, Onder M (2008) An Investigation of Efficacy of Topical Niacinamide for the Treatment of Mild and Moderate Acne Vulgaris. J Turk Acad Dermatol 2: jtad82402a.

25. Draelos ZD, Matsubara A, Smiles K (2009) The effect of $2 \%$ niacinamide on facial sebum production. J Cosmet Laser Ther 8: 96-101.

26. Hao J, Chang-yi LI (2016) High dose Niacinamide in the Treatment of Acne Vulgaris: a pilot study. Chinese J Aestetic Medicine 25: 54-59.

27. Ghyczy M, Nissen HP, Biltz H (1996) The Treatment of Acne Vulgaris by Phosphatidylcholine from Soybeans with a high content of Linoleic acid. J Appl Cosmetol 14: 137-145.

28. Morganti P, Berardesca E, Guarneri B, Guarneri F, Fabrizi G, et al. (2011) Topical clyndamicyn $1 \%$ vs. Linoleic acid rich phosphatidylcholine and nicotinamide $4 \%$ in the Treatment of acne: a multicenter-randomized trial. Int J Cosmet Sci 33: 467-476.

29. Vargas-Diez E, Hofmann MA, Bravo B, Malgazhdarova G, Katkhanova OA, et al. (2014) Azelaic acid in the Treatment of acne in adult females: case report. Skin Pharmacol Physiol 27: 18-25.

30. Ozcan M (2005) Antioxidant activity of seafennel (chritmum maritimum L.) essential oil and rose (Rosa Canina) extract on antioxidant activity of seafennel (crithmum maritimum L.) essential oil and rose (rosa canina) extract on natural olive oilnatural olive oil. Acta Alimentaria 29: 377-384.

31. Uter W, Johansen JD, White IR, Menne' T (2019) Contact Dermatitis, John Wiley \& Sons Ltd, Oxford, UK.

32. Nichols JA, Katiyar SK (2010) Skin photoprotection by natural polyphenols: anti-inflammatory, antioxidant and DNA repair mechanisms. Arch Dermatol Res 302: 71-83. 